TRAMES, 2008, 12(62/57), 3, 355-365

\title{
THE MOBILE FAMILY GALLERY? GENDER, MEMORY AND THE CAMERAPHONE
}

\author{
Anna Reading \\ London South Bank University
}

\begin{abstract}
This article suggests that the study of memory in the 21 st century needs to be understood within a rapidly developing techno-social context that includes wearable and portable mobile technologies. Drawing on a pilot study involving depth interviews on camera phone use by women and men in London in 2006, the paper addresses how mobile camera phones are being used to capture and share personal image memories. The study suggests that mobile memories enable the articulation of complex gendered identities that traverse established boundaries of men and women's lifeworlds. This in turn has implications for the conceptualisation of the history of memory. Every day that we 'wear' a mobile phone our personal embodied memory is a multimedia networked gallery. It may seem the milieux de mémoire are dissolving into the lieux de mémoire of our own bodies, but if we look closely then every lieux is also a milieux.
\end{abstract}

DOI: $10.3176 /$ tr.2008.3.10

Keywords: mobile phones, memory, gender, photography, family

\section{Introduction}

The mobile cameraphone is now ubiquitous. Over the past 25 years, the 'mobile' 'cell phone', 'handy', 'ketai' or 'pele-phone' has gone from being a sci-fi fantasy to something carried as commonly as the wrist watch (Agar 2003:3). This is as much in evidence in post-industrial societies such as Japan and the UK, as well as parts of the developing world, where it can allow poorer users to leapfrog or abandon unreliable landline technologies (Anderson 2007).

Mobile phones are also increasingly sophisticated. Many now include cameras, video cameras and sound recorders as standard features and allow users to capture and record images and sounds. Mobile phones include archives for images, short video clips, and text messages, as well as diaries, organisers and memory prompts. Third and fourth generation technology provides for access to the global public memories of the World Wide Web and for the circulation and distribution on a 
mobile basis of personal multi-media memories. Memory is a major driver in the future of mobile technology trends (Next Generation Mobile Trends and Technologies 2008).

Just as the shift from the public clock to the private timepiece or wrist watch shifted the individual's relationship to the knowledge of time from the public domain to the private/body, so too the mobile phone suggests profound changes to human beings relationships to knowledge, communication and recall. With their portability or rather wearability, mobility and multi-purpose memory functions to what extent is the mobile phone reconstituting memory practices, languages and forms? In what ways is gender important to this? Drawing on cultural theories of memory, as well as literature on cell phones, I begin by considering the theoretical implications of mobile digital media's potential for reconfiguring memory practices in what Kath Weston has conceptualised as gendered spacetime. ${ }^{1}$ The article then explores this empirically through a research project conducted in 2006 investigating gender and the mobile phone in relation to memory practices in London, UK. The empirical data I use focuses, in particular, on how mobile camera phones are being used by women to record and circulate domestic images of the 'family'. These, it is argued, constitute important gendered memory practices that are traversing established boundaries between public and private memories. This in turn suggests that we need to re-conceptualise personal and cultural memory to take into account mobile digital technologies in the 21 st century.

\section{Theorizing gender and mobile digital memory}

Although the telephone, generally, has been relatively neglected by communications scholars (Goggin 2006:3), a small number of studies have suggested the importance of gender in relation to the fixed line telephone (Martin 1991; Moyal 1992). Earlier work by Lana Rakov (1993), for example, demonstrated how women used the telephone to extend their capacity to mother when separated spatially from their children. Literature that addresses the impact of photography and digital culture also points to the gendered memory potential of mobile phones in terms of their imaging functions. Susan Sontag (1973) has shown how the earliest popular use of photography was in terms of memorialising family members. According to Daniel Rubinstein, the camera phone is redefining the popular use of photography so that it is used to record and elevate the ordinary and the everyday (Rubinstein 2005:117). This is echoed by Kato and Okabe who have explored the potential for a newly developing image language for communicative functions of phones (Kato et al. 2005:300-310).

Although these studies do not examine camera phone imaging specifically in relation to memory, or gender, what they do suggest is that the camera phone may

Kath Weston in Gender in Real Time (2002,) drawing on Einstein's Special Theory of Relativity (1905), argues for an understanding in which time and space are not separate conceptual entities but are integrated conceptually as spacetime in which gender is a constituent feature. 
offer, potentially, a digital reconfiguration of the project to photographically remember the family. Men and women have the capacity with their phones to capture and carry visual reminders of their own family from moments within everyday domestic life.

If this is the case, what kind of memory are we talking about? Is the mobile phone a personal memory prosthetic, or is it also a cultural and collective memory form? What broader theoretical implications might mobile media suggest in terms how we conceptualise memory? How is gender relevant to this?

Historical perspectives on personal and cultural memory are frequently concerned with how aspects of social communication have changed over time along with different memory forms and practices (Ong 1982; Clanchy 1993). While they do not yet take into account mobile technologies, they provide some clues in that approaches that historicize memory practices and forms examine the concomitant shifts in technologies that can be used to record the past outside of human consciousness. Le Goff, for example, argues that there have been five phases of collective memory, from the first which refers to the collective memory of people without writing, to the current phase with its vast mass mediated potential for memory expansion (Le Goff 1992:54-5). Ong (1982) maintains that each phase of memory, historically, is configured through a different relationship of human beings to time and space. Pierre Nora's classic study (1996) argues that there has been a break down in modern societies from what he characterizes as milieux de mémoire to lieux de mémoire. Building on this, Paul Antze and Michael Lambek suggest that this leaves us with only one fixed point of reference, the lieu or site provided by our own bodies (Antze and Lambek 1995: xiii).

The mobile phone, in late capitalist societies, with its portable proximity to the site of memory offered by our bodies may be understood as a memory prosthetic situated at the interstices of the public and private. Hence, Leopoldina Fortunati, in a study of the use of the mobile phone in Italy, argues that we need to examine its implications for blurring and extending the boundaries between human's and machines (Fortunati 2002:24-62). The mobile is so close to people's bodies it is 'sucked' inside people's clothing, resulting in adaptations to clothing and accessories (Ibid: 58). This 'wearability' of the mobile phone (Campbell and Park 2008:1) is arguably different for men and women, however. Many women's handbags now include a special pocket for their mobile phone, but most men carry their phones on a belt or inside a jacket pocket. In some cultures the phone is carried in a holster replicating a gun (Horst and Miller 2006).

Further, contrary to Nora's argument that the social milieux of memory are simply collapsing into the body, the mobile's potential to link the gendered body to a digital network suggests the concomitant development of a new techno-social milieu in terms of the historical development of memory. This is, perhaps, more easily understood in considering not only how the mobile phone has gained a place of proximity to our bodies but also how it is used by men and women differently on display outside of their bodies. For 60 per cent of women in one study the phone in public was always placed outside of the body in a position of 
display, as a talisman to keep them safe (Plant 2002). Women in the UK were found to use their phones as a 'barrier signal' or a 'personal bodyguard' to deter unwanted people from chatting them up or getting too close (Fox 2006:14). In memory terms, the phone has the potential to act as a reminder to the owner of their techno-social connections to others, but it is also a reminder to those around the owner, to strangers and to potential assailants, that although the person appears to be alone, they are part of larger network of family, friends, work colleagues as well as linked to the state and emergency services.

Mobile phones extend what Kenneth J. Gergen (2002:228) calls 'absent presence', in his view a divided consciousness, but, perhaps, what may be more accurately described as linked presence, with the mobile enabling men and women to traverse the here and there, the present and the past. Further, studies also suggest that how the mobile traverses spacetime is gendered. Puro argues in relation to mobile use in Finland that women use their mobiles for a wider range of purposes than men, using them for security and micro-co-ordination of the household, often at work (Puro 2002:19-29). Likewise, recent work on mobile phones in Japan also suggests they are important for micro-coordination of the household for women (Dobashi 2005:219-237).

\section{A mobile album or gallery?}

Any empirical research on the practice and use of the mobile needs to be understood within different social and communicative contexts (Kim 2002:63-4). In the UK where my research was conducted, nearly 90 per cent of people between the ages of 16 and 34 owning or using a mobile phone (Young People and ICT Survey, Department for Education and Skills). This also needs to be contextualised within the varying articulations of gender in different cultures, some of which may be shared across cultures and some of which may be specific to certain cultures. Thus, Dobashi's observation that women in Japan make more use of the mobile in domestic settings than they do of other digital technologies such as the PC, which is deemed to be the property of the family and household, needs to be understood in a context in which most married women still do not work (Dobashi 2005:227). In contrast, in the UK, where my research was conducted, it is not insignificant that over $50 \%$ of mother's with children under five work. $44 \%$ of lone women parents go out to work. $73 \%$ of women aged 16 to 59 were economically active, compared to $84 \%$ of working age men. (http://www. womenandequalityunit.gov.uk/women_work/key_facts.htm). With the rise in the UK of women with children now working, the majority of children under school age are now cared for through predominantly commodified relationships such as private nurseries, au-pairs, childminders and nannies. 64 per cent in 2005/6 were in pre-school settings (Changing Lives of Today's Children 2007)

The material that follows on gender, memory and camera phone images comes from a study conducted in London in April and May of 2006. The study began with a research assistant and me keeping a diary of our own mobile phone use and 
observations of the use by others over a period of several weeks to provide the basis for thinking about the framework for our research instruments. We then conducted a qualitative research project that involved 20 respondents from a variety of cultural backgrounds, aged between 20-35, with 3 focus groups with four participants each and interviews with the rest. Interviews and focus groups were between 1-2 hours long.

Respondents were asked first to talk about their mobile phone in terms of how they carried it, where they charged it up, when and where they would turn it on and off or into different modes. They were then asked what kind of data they kept in it, how they use it in terms of texting, voice calls and multimedia messaging; whether and how they used their phones various potential forms of connectivity including MMS (multi-media messaging service), bluetooth, file transfer programs, memory cards, and connections to the World Wide Web. Finally, they were asked to choose a favourite camera phone image they had stored and talk about its context and use. In what follows, I focus primarily on one theme that emerged from female respondents that relates to their use of their mobile phone to record and circulate images of children and family.

The mobile phone to the respondents in this study was found to be an intensely personal memory device. Women 'wear' their phone even within the home. Women said that they would not look at their partner's phone or answer it as it contained material that was private to them, rather like a personal diary. Yet at the same time, it was evident that the memories in the form of various digital data within the mobile phone were considered in some ways contingent and temporary. Most women described keeping a material back up of certain kinds of data - a paper phone book or birthday book - for example that replicated their contacts list. Respondents also described how they liked to keep particular messages from partners. They would then mourn the loss of significant text messages such as those from the beginning of a personal relationship when they had to delete them to make more space or they had been unable to transfer them to new phone. One woman went so far to keep her old phone in her wardrobe because it had all her old text messages on. She didn't know how to transfer them and she no longer used the phone but she couldn't bear to actually lose them.

In contrast, few respondents described taking camera phone images with a view to later printing them out. In addition, the temporal relationship of their photos also seemed different from material photos. 'Old' photos on a phone were defined as those that had been taken a year ago: "Oh god that's from ages ago. That was from last summer." (Respondent B, female, aged 30, Focus Group). Partly, this is because the images themselves are not necessarily taken with the expectation that they will be kept but also that they are defined by the 'life' of the phone itself enmeshed in a local/global political economy. In the UK mobile market, the mobile phone contract encourages frequent upgrades and the subsequent built in obsolescence of the phone.

They are kind of photo albums but they aren't lasting ones. I know when I get a new phone I'm not going to realistically download them anywhere or print them out or anything. (Respondent C, female, aged 30, Focus Group.) 
You only have your phone for a year though don't you? Maximum a year and then you upgrade so anything older than a year is old. (Respondent D, female, aged 28, Focus Group.)

What is recorded is also different from the kinds of images taken with a conventional camera or digital camera. Always having the phone on them meant that respondents described how it was possible to take photos of events they did not predict as well as the mundane and ordinary aspects of everyday life. Because the user can see instantly what has been recorded or captured, this is also shifting what is kept and what is not. In this way, the site of the mobile camera phone suggests a less fixed and more transient form of memory. As one respondent said:

I'm getting quite used to the idea of 'well I can record that and you know what I can just delete it' so you start taking photos of small things because you can. (Respondent D, female, aged 28, Focus Group.)

While most respondents did not use the video function, due to the amount of digital memory space it takes up, most respondents reported using the camera function on their phones regularly to capture, store, process and send or share memories. With camera phone images, unlike conventional photos, they have the potential to be sent and forwarded, instantly, so that the memories potentially could become rapidly extended beyond the original recipient and unanchored from their original context. An example of this was a humorous image taken by one female respondent of herself with friends with limes in their mouths when they were out one evening together. She sent the image to one friend who quickly circulated it to others beyond her circle.

However, although the mobile phone has the potential for memories to be shared through gendered spacetime beyond the phone via a variety of means, evidence suggests that the practices associated with memory sharing from camera phones are more complicated. Female respondents described how they bought their phones with the intention of being able to send photos via multimedia messaging to distant family members. However, they then often found the technology didn't seem to support it in the way they had imagined, or they couldn't seem to get the technology to work or the service itself was too expensive for regular sharing in this way. One respondent, who was residing in the UK, whose mother lived in Australia, stated:

When my niece was born I wanted to take photos and send them to my mum instantly, but it doesn't work. (Respondent E, female, aged 30, Focus Group.)

Nevertheless, in this study there were more women than men who sent multimedia messages. Images were sent between a small number of recipients, but rarely uploaded to the web or sent via Bluetooth. Although, young women of school age tended to share images via the World Wide Web using one of the many moblog (mobile blogging) or social networking sites now available, because this was much cheaper than using MMS. Both men and women seemed, on the whole, to share their camera phone images with people within their circle of immediate family and some work colleagues. Further, the handset itself was often used to 
display and share images with people who were physically co-present at home, in the pub, the café or in the office.

Cameraphone images, in practice, then are not necessarily posted on the web or emailed to groups of people since respondents described how they were often only shared with one or two people who tended to have some kind of relevancy to the photo, with many of the favourite images of those saved were children either the respondents or those of other family members. Thus in the UK context in this study, the mobile camera phone is used more like a portable 'family album' rather than its potential of a globally networked memory prosthetic. It is also thus being used to deepen established relationships rather than extend memories into a wider circle.

However, where this seemed to be different was in terms of porting memories of one's domestic or private life into a public workplace context or vice versa. Women and men described how they felt able to show colleagues recent images of their children on their handsets at work, in ways that would not be possible with the conventional family album. Others described sharing images that essentially related to porting memories of child care between realms in other ways. One female respondent who worked as a nanny said why she took camera phones images of the day's activities with the children in her care.

I pretty much just take photos of the children at work so I can show them to the mum when she comes home from work so that she can see what a lovely time we've had. (Respondent G, female, aged 27, Interview.)

Another described how both her mum and she would take photos if they were babysitting to share at the same time across spacetime or later when they were physically co-present.

My mum does that [take mobile phone photos] when she's babysitting for my brother. Halfway through the night she'll send him a picture that she's taken. Whenever my niece has fallen asleep or does something she'll take a picture. (Respondent F, female, aged 30, Interview.)

What this suggests in terms of this blurring of time in space in practice is that mobile images are being used to connect and traverse the public and private. They are used, in effect, as a form of public testimony in relation to the more private world of parenting and childcare. Lev Manovitch (2002) has described this blurring of hitherto separate private and public realms as a central feature of digital cultures. In terms of memory, I would suggest the cameraphone is being used to traverse the gendered contradictions of spacetime in UK post industrial society, where children are often cared for by women other than the mother. This happens even within commodified relationships such as with a nanny, childminder or nursery.

How this is being instantiated in mobile memory terms is also evidenced by the language of the software used to view images on mobile phones. What users have on their phones is not in fact an 'album'. Mobile camera phones generally tend to have a menu that includes a 'Gallery' or 'Galleries' where users store their images and videos. The language and metaphors of such software is certainly not without meaning, as Friedman suggests in 'Making Sense of Software' (Friedman 1993). The term 'Gallery', in terms of memory and language, re-situates the personal 
images of family and friends within the domain of the public sphere with its concomitant connotations of accessibility, creativity, commerciality, status and display. This is rather than situating the images within the private sphere, with the term 'album', and its concomitant associations of associations of the personal, domestic, the everyday and mundane. Likewise, the software on mobile phones often refers to 'Archive' and respondents talked about 'archiving' their texts or images. Rather than the personal album or shoebox of memories in the dusty cupboard, the mobile 'archive' suggests that even in relation to their own personal memories the individual now performs the role of a public librarian or trained archivist, ordering and maintaining documents relating to the past with its concomitant status, authority and location within the public realm of the lifeworld.

Respondents also stressed that they used images via their phones to provide authority for a story or to legitimate something. "It saves you from having to talk about it. You can just go "Oh here look" said one respondent. Interestingly, studies on work and gender roles have consistently observed how parenting and mothering in particular is difficult to describe in terms of conventional capitalist work norms and outcomes. In What Mothers Do Naomi Stadlen (2004) describes the difficulty for a mother who has spent all day with her infant describing exactly what it is that she has achieved. As a result it is hard to legitimate the labour she conducts in the day with her baby or children in a society that values and pays for products and outcomes. The camera phone memories that a nanny shares with her employer, or that a mother shares with the father of her baby, or a grandmother sends to her daughter, via the handset, Bluetooth or MMS constitute the practice of attempting to digitally bear witness to, memorialize and legitimate aspects of people's lifeworlds, particularly parenting, within a gendered political economy that seeks to devalue them. To put a child to sleep takes time, effort and love that cannot be easily summarized in a text. But an image of a child asleep or eating their dinner bespeaks the memory of the mundane and often repetitive, yet extraordinary, multi-levelled process that constitutes child-care. It is also for the men and women who utilize in the workplace 'the mobile gallery' a way of remembering in the public realm and the conventionally forgotten domestic realm. In this respect this study suggests that the memory potential of the mobile camera phone enables the articulation of more complex gendered identities that traverse people's lifeworlds.

\section{Conclusion: mobile memory as techno-social lieux-milieux}

With mobile camera phones, because they are wearable (rather than simply portable) and, increasingly, always carried, like door keys, watch or wallet, then what is captured and recorded is different from the camera, notebook or laptop. The mobile camera phone allows for a record of everyday life (Kato et al. 2005: $305)$ but a record that is impermanent. In this sense the mobile phone is more like an extension of personal memory.

At the same time, mobile memories are captured within a context of potential and actual polylogical sharing, along with the phone itself, since it is always with 
us, very often part of the event, as Gerard Goggin (2006:149) notes. In this way, mobile memories are an extension of the conversation, closer to oral memory than other memory forms, with the visual images we capture, retain and share becoming an extension of our speech.

Further, mobile memories seem to provide new gendered possibilities in terms of the languages and practices of memory that may be used to constitute and reconstitute identities. Although based on the culturally specific evidence provided by a small sample of UK respondents, what this study points to also has resonance with studies elsewhere and suggests that mobile phones are used to help bridge or traverse the gendered contradictions of late capitalism (Ibid:86) Women are using the memory potential of camera phones to capture, record and share images of the everyday in terms of parenting and childcare. This enables them to rearticulate and legitimate through mobile memories aspects of their gendered identities that might otherwise remain unrecorded. This may both intensify and resolve the social and gendered contradictions of the everyday.

This also suggests something more profound in terms of theorising memory. The mobile camera phone with its portable proximity to the site of memory offered by our own bodies is a multimedia memory prosthetic situated within the interstices of the social and the individual, the cultural and communicative. It traverses the public and the private, the material and the virtual. It re-localises time and space. Any transdisciplinary study of memory in the $21^{\text {st }}$ century needs to be understood within this rapidly developing techno-social context that includes mobile technologies. Every day that we 'wear' a mobile phone our personal embodied memory is also a multimedia networked gallery. It may seem the milieux de mémoire are dissolving into the lieux de mémoire of our own bodies, but if we look closely then every lieux is a networked milieux.

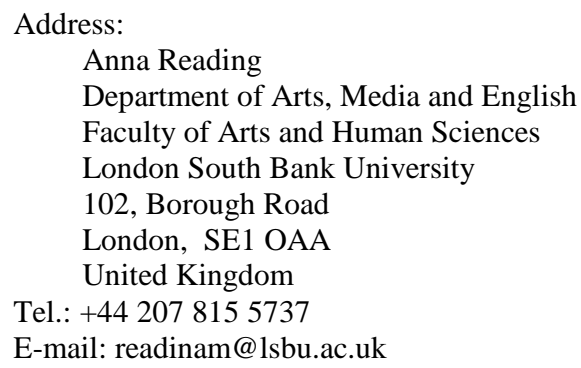

\section{References}

\footnotetext{
"Adult mobile phone ownership or use: by age, 2001 and 2003". Social Trends 34. Accessed online in 21.4.08 at: http://www.statistics.gov.uk/STATBASE/ssdataset.asp?vlnk=7202

Agar, Jon (2003) Constant touch: a global history of the mobile phone. Cambridge: Icon Books. Anderson, Tatum (2007) "Mobile phone lifeline for world's poor" BBC News, Monday 19 February. Accessed online in 21.4.08. at: http://news.bbc.co.uk/1/hi/business/6339671.stm
} 
Antze, Paul and Michael Lambek (1996) "Introduction: forecasting memory.” In Tense past: cultural essays in trauma and memory, xi-xx. London: Routledge.

Campbell, Scott W. and Yong Jin Park (2008) "Social implications of mobile telephony: the rise of personal communication society". Sociology Compass 2, 2, 371-387.

Clanchy, Michael T. (1993) From memory to written record: England 1066-1307. London: Blackwell.

"Changing lives of today's children." Social Trends (2007) 37. Accessed online in 21.4.08 at: http://www.statistics.gov.uk

Dobashi, Shingo (2005) "The gendered use of Keitai in domestic contexts". In Personal, portable, pedestrian: mobile phones in Japanese life, 219-236. Mizuko Ito, Daisuke Okabe, and Misa Matsuda, eds. Cambridge, Mass: MIT Press.

Friedman, Ted (1993) "Making sense of software." Accessed online in 21.4.08 at: http:// cyber.eserver.org/friedman/

Fortunati, Leopoldina (2002) "Italy: stereotypes, true and false". In Perpetual contact: mobile communication, private talk, public performance, 42-63. James E. Katz and Mark Aakhus, eds. Cambridge: Cambridge University Press.

Fox, Kate (2006) "Mobile life. A survey of 16,500 people for the LSE/Carphone Warehouse". Cited in (accessed online in 21.4.08): http://www.guardian.co.uk/uk/2006/jul/23/ mobilephones.davidsmith.

Gergen, Kenneth van (2002) "The challenge of absent presence." In Perpetual contact: mobile communication, private talk, public performance, 227-241. James E. Katz and Mark Aakhus, eds., Cambridge: Cambridge University Press.

Goggin, Gerard (2006) Cell phone culture: mobile technology in everyday life. London: Routledge.

Garcia-Montes, Jose, Domingo Caballero-Munoz , and Marino Perez-Alvarez (2006) "Changes in the self resulting from the use of mobile phones". Media Culture and Society 28, 1, 67-82.

Horst, Heather, A. and Daniel Miller (2006) The cell phone: an anthropology of communication. Oxford: Berg.

Kato, Fumitoshi Kato, Daisuke Okabe, Mizuko Ito,and Ryuhei Uemoto (2005) "Uses and possibilities of the Ketai camera". In Personal, portable, pedestrian: mobile phones in Japanese life, 300-310. M. Ito, D. Okabe, and M. Matsuda, eds. Cambridge. MA: MIT Press.

Katz, James E. (2006) Magic in the air: mobile communication and the transformation of social life. New Brunswick, NJ: Transaction Publishers.

Katz, James E. and Mark Aakhus, eds. (2002) Perpetual contact: mobile communication, private talk, public performance. Cambridge: Cambridge University Press.

"Key facts on women in the labour market. UK Government Equalities Office." Accessed online in 21.04.08 at: http://www.womenandequalityunit.gov.uk/women_work/key_facts.htm

Kim, Shin Dong (2002) "Korea: Personal meanings". In Perpetual contact: mobile communication, private talk, public performance, 63-79. James E. Katz and Mark Aakhus, eds. Cambridge: Cambridge University Press.

Le Goff, Jacques (1992) History and memory. S. Rendall and E. Claman, trans. New York: Columbia University Press.

Manovitch, Lev (2002) The language of new media. Leondardo Books.

Martin, Michaele (1991) Hello central? Gender, culture and technology in the formation of telephone systems. Montreal: McGill- Queens University Press.

Moyal, Ann (1992) "The gendered use of the telephone: an Australian case study". Media, Culture and Society 14, 51-72.

"Next generation mobile trends and technologies" (2007). Accessed online in 21.4.08 at: http://www.3g.co.uk/PR/March2005/1240.htm

Nora, Pierre, ed. (1996) Realms of memory. 3 Vols. A. Goldhammer, trans. New York: Columbia University Press.

Ong, Walter J. (1982) Orality and literacy: the technologising of the word. New York. Methuen.

Plant, Sadie. (2002) On the mobile: the effects of mobile telephones on social and individual life. Accessed online in 21.4.08 at: http://www.motorola.com/mot/doc/0/234_MotDoc.pdf 
Puro, Jukka-Pekka (2002) "Finland: a mobile culture". In Perpetual contact: mobile communication, private talk, public performance, 19-29. James E. Katz and Mark Aakhus, eds. Cambridge: Cambridge University Press.

Rakov, Lana (1993) Gender on the line: women, the telephone, and community life. Chicago: University of Illinois Press.

Rubinstein, Daniel (2005) "Cameraphone photography: the death of the camera and the arrival of visible speech." The Issues in Contemporary Culture and Aesthetics 1, 113-118.

Sontag, Susan (1973) On photography. New York: Delta.

Stadlen, Naomi (2004) What mother's do: especially when it looks like nothing. London: Piatkus.

"Young people and ICT survey" (2001) NGfL Research and Evaluation Series leaflet. Department for Education and Skills. Accessed online in 21.04.08 at: http://www.dfes.gov.uk/research/ data/uploadfiles/ACF2AB1.pdf 